density in the ionosphere is rising comparatively slowly or is near a stationary point: that is, the optical eclipse might be observed in the morning, but well after sunrise, the particle eclipse near noon. The low latitude of the eclipse track suggests another considerable advantage, the eclipse phenomena unrolling at such a low speed that the cumulative effects on ionisation may well outweigh the 7 per cent defect in magnitude of the eclipse. It would appear most desirable that an adequate organisation should be worked out for observations on the optical eclipse near Delhi, with corresponding observations on the particle eclipse.

The Superintendent of the Radio Research Station, Slough, would be grateful for information as to the station of origin of pulse signals on a frequency of $3.56 \mathrm{mc} . / \mathrm{sec}$. (pulses at 50 per sec.) which were accidentally observed at Slough during the control experiments for the eclipse. The pulse signals ceased at 2020 G.M.T. on Sept. 1 and at 2100 on Sept. 2. The echo pattern, showing marked magneto-ionic splitting, was recorded simultaneously with that from local pulses; the comparison of distance and direction data might yield useful results.

1 Appleton, Observatory, March 1932.

Appleton and Naismith, Proc. Rou. Soc., A, 137, 36 ; 1932.

Chapman, Mom. Not. Roy. Ast. Soc., 92, 413; 1932

Miller, Mon. Not. Roy. Ast. Soc., 92, $421 ; 1932$

Appleton and Chapman, NATURE, 129, 757, May 21, 1932

2 Appleton and Naismith, loc. cit

3 Schafer and Goodall, Proc. I.R.E., 20, 1131 ; 1932

4 Ranzi, Nature, 130, 368, Sept. 3, 1932.

\title{
Current Constructive Theories in Psychology*
}

\section{By Prof. Beatrice Edgell}

$\mathrm{O}^{\mathrm{N}}$ Aug. 29 there occurred the tercentenary of one who is often called 'the father of English psychology', John Locke, 1632-1704. His "Essay concerning Human Understanding " is primarily a theory of knowledge, not a system of psychology, but none the less there is much of psychological interest in the Essay, and it has had a profound influence on empirical psychology in the eighteenth and nineteenth centuries. We may regard it as a misfortune that what he described as a " historical plain method" should have been interpreted as a genetic study, and that his doctrine of simple and complex ideas should have been translated into a doctrine of psychological elements and compounds; but such has been the case. Historians trace a straight line of descent from the Essay of Locke to the "Analysis of the Phenomena of the Human Mind " by James Mill, and thus claim Locke as a founder of the Association school.

It may seem a far cry from 1632 to 1932 , but I want to consider some of the differing constructive theories of learning and knowledge offered by the psychologists of to-day in the light of the unreconciled methods and principles which find expression in the Essay.

We find first and foremost in the Essay a confusion of logical and psychological analysis; secondly, we find a theory that attributes the union of discrete ideas to their accidental association in time, introduced as an afterthought to the theory that ideas are united by the perception of their connexion or repugnancy.

To begin with the confusion of logical with psychological analysis. As Prof. Gibson has pointed out in his book " Locke's Theory of Knowledge ", at the time at which Locke was writing, the distinction between the elements of knowledge attainable by logical analysis and the simple beginnings of-knowledge attainable by genetic study was a distinction which it was wellnigh impossible for a writer to draw. Growth and development were conceptions which had a very different colour-

* From the presidential address to Section $\mathbf{J}$ (Psychology) of the British Association, delivered at York on Sept. 5 . ing from what they have for us to-day. They were, moreover, conceptions which had no literal application to knowledge. Knowledge for Locke was a structure the validity of which could be tested by taking it to pieces. Just as a logical analysis of the ultimate items into which, say, a building could be resolved and an inquiry into the material out of which it arose might lead one to much the same catalogue of stones and beams, so a logical analysis of knowledge into its elements seemed to have the same issue as an inquiry into the beginnings of knowledge. That which is simple in its content is easily confused with that which is simple in its origin. It is this confusion which lays Book II. of Locke's Essay open to much misunderstanding. Having in Book I. denied that mind is possessed of ideas at birth, and having claimed that all knowledge is founded upon, and derived from, experience, Locke seems by his account of the ' simple ideas' of sensation and reflection and of the 'complex ideas' built upon them to be offering a psychological constructive theory of knowledge.

There is much of great psychological value in this second book : Locke's frequent appeal to concrete illustrations, his references to children and animals, the famous citation of Molineux's problem whether a man whose sight was only restored to him in adult life would be able to distinguish by sight between a sphere and a cube. The book also contains his striking chapter on retention, vivid through its analogies but of paramount importance for psychology by reason of the statement added in the second edition: "This laying up of our ideas in the repository of the memory signifies no more but this, that the mind has a power in many cases to revive perceptions which it has once had, with this additional perception annexed to them, that it has had them before, and in this sense it is that our ideas are said to be in our memories, when indeed they are actually nowhere; but only there is an ability in the mind when it will to revive them again, and as it were paint them anew on itself, though some with more, some with less difficulty; some more lively, and others more

No. 3280, VoL. 130] 
obscurely" (II. x. 2). Here there is a glimpse of a conception which might have done much to correct the atomism encouraged by the 'blank paper' and 'cabinet' metaphors in other passages.

When mind is compared with an empty cabinet which is furnished by the simple ideas of sensation and reflection, simple ideas are being treated as the psychological origin of knowledge. When, on the other hand, Locke tells us that simple ideas are unanalysable, are not distinguishable into different ideas, and are those in which men agree when they clear away verbal misunderstanding, we have simple ideas as the materials of knowledge in the logical sense. If we look at the simple ideas listed together, we find the same confusion: the items 'colour', 'sound', 'pleasure', 'pain' might be interpreted as psychologically simple, but what of the items 'existence', 'unity', 'power', 'succession'?

In his account of complex ideas, Locke starts with what purports to be a psychological account of how they are formed-namely, the operations of compounding by putting together several simple ideas, and of abstracting by " separating them from all other ideas that accompany them in their real existence". These operations are set side by side with the operations of comparison and seeing relations. Locke holds that such operations are not present in animals. The complex ideas of animals are apparently combinations of simple ideas given to, not made by, the animal. "They take in and retain together several combinations of simple ideas, as possibly the shape, smell and voice of his master make up the complex idea a dog has of him, or rather are so many distinct marks whereby he knows him ; yet I do not think they do of themselves ever compound them, and make complex ideas" (II. xi. 7). These operations of mind in building complex ideas are never brought into clear relation with the operation which constitutes know. ledge-namely, " perception of the connection of and agreement, or disagreement and repugnancy, of any of our ideas ". Cutting across his attempted psychological account of how complex ideas come to be formed, Locke gives a logical classification of complex ideas according to the nature of their object or reference : there are ideas of modes, of substances, and of relations. In this we have another example of the confusion of the psychological and the logical point of view, or shall one say of transition from one to the other without any realisation of the change in outlook?

No orthodox psychologist from the time of Wundt onward would have admitted for a moment that his acceptance of sensations as psychological simple elements was due to logical analysis. $\mathrm{He}$ would have declared that it was due rather to the analysis of physiological events, namely, the simple stimulation of a sensory receptor and the resultant excitation of the central nervous system.

I question whether any psychologist who sets out from simple sensations is really determined by a search for what is primitive in experience. That we do not experience simple sensations as such is, of course, admitted on all hands ; when treated as elements they are often said to be reached by 'hypothetical' analysis. What I want to suggest is that such analysis is the outcome of logic, not psychology. The method implies that perceptual knowledge is a structure, the logical analysis of which will yield the bricks out of which it is made. This is a teaching derived from Locke's Essay. The use to which the Association school put Locke's theory of association rests on this doctrine. The theory is given in a section added to the fourth edition of the Essay, and was put forward as a theory to explain strange aversions and likings, prejudices and errors. It is never put on a level with the synthetic processes of knowledge wherein there is perception of a relationship between ideas. Association is thus primarily a way of uniting items which are discrete and have no intrinsic connexion with one another.

Gestalt psychology to-day is never tired of proclaiming itself as a revolt from associationism. Even if we believe that associationism in pure psychology is dead, how far may it, nevertheless, be true that Gestalt is fighting a present-day attitude of mind which had its historical foundation in Locke's confusion of logical analysis with an inquiry into psychological genesis?

Gestalt psychology would claim that no constructive explanation can be satisfactory which sets out from such elements as sensory events or reflex responses, and attempts to build up the experienced phenomena of human awareness and behaviour by the synthetic method. Perceptual awareness of a situation and responsive behaviour must, on its view, be taken in toto. The explanation of why just 'this' is perceived rather than 'that', must be sought in the physical constitution of the immediate environment and in the total condition of the organism. The school sets itself the task of studying the conditions in the stimulating situation which determine the perception of this pattern rather than that. It is always the pattern or configuration as a whole which has to be explained. Much experimental work has been done and valuable information obtained, particularly in the field of visual perception.

Whereas for the 'orthodox' school-if there is still a school capable of claiming this adjective' meaning' in the form of memory images, actual or potential, comes in as an ingredient in the complex perception of an $x$, for Gestalt, meaning may lie in the nature of the sensory pattern or total organisation. To take an example, size or shape perceived in indirect vision is not 'apparent' size or shape modified by the memory of ' real' size and shape ; the size or shape actually perceived is due to the sensory pattern of the whole field.

It is 'organisation' which for Gestalt replaces the conception of association. The so-called association of contiguity is never mere collocation in time or space. It is always an instance of organisation. "Organisation is not at all an aggregation of indifferent material. . . . If association is a consequence of organisation, it must also depend upon the mutually relative properties of what is or shall be organisated". (Köhler, "Gestalt Psychology", p. 211). 
When we turn to the question, How do organisations arise? we may not be wholly satisfied with the answers at present forthcoming. There are the sensory organisations or patterns the conditions of which are being experimentally investigated. Here the relative importance of the environmental and the intra-organic factors stands in need of elucidation. Descriptive terms such as ' closure', 'nearness', 'pregnancy', 'symmetry' summarise the present formulations of experimental findings. There are also the organisations said to be created intentionally. Here the 'self' and 'attitudes' are called in as explanatory concepts, and with them we pass over into a speculative region of tensions and dynamic relations in the brain field, a somewhat misty region in our present state of knowledge.

The contemporary representatives of Locke's doctrine of association are the behaviourists. According to this school, man is born with certain native responses to definite conditions in his environment : his unconditioned reflexes. He 'learns' or acquires new responses when an original response is extended to a different situation or when an original situation is made to evoke a different response.

'This acquirement is the result of ' conditioning '. All conditioning depends upon the temporal arrangement of the factors in the stimulating situation and upon the structure of the animal's nervous system. Conditioning is a scientific formulation of the facts noticed by Locke as association. "Custom settles habits of thinking in the understanding, as well as of determining in the will, and of motions in the body: all which seems to be but trains of motions in the animal spirits, which, once set agoing, continue in the same steps they have been used to ; which, by often treading, are worn into a smooth path, and the motion in it becomes easy, and as it were natural ... and are therefore called so, though at first they had no other original but the accidental connexion of two ideas, which either the strength of the first impression, or future indulgence so united, that they always kept company together in that man's mind as if they were but one idea" (Essay, II., xxxiii., §§ 6 and 7). In the language of behaviourism, such a man is ' conditioned' to respond to the second idea as he originally did to the first. As in associationism the complex phenomena of mind were constructed from the simple ones by association, so in behaviourism all the complex phenomena of human behaviour are constructed from the simple units of reflex responses by conditioning. Behaviourism presents us with a tidy system wherein everything hangs together. The whole of man's thought (speech) and conduct is theoretically capable of being explained deductively from his original reflexes subject to conditioning.

There are other contemporary schools wherein association figures as a great principle of linkage, but in each of them some condition over and above bare sequence is recognised. In the psychology of Prof. McDougall, association by bare contiguity has a place, but he also lays great stress on the learning that implies a thread of purposive interest. The $a, b$, and $c$ that are associated together are members of what Prof. Stout terms a conative unity'. This interest would be an essential feature in the experience acquired in working out any instinctive tendency. Membership of a purposive whole is in principle a radical departure from association by temporal contiguity.

In psycho-analysis there is again great emphasis on association and its opposite, dissociation. The old forms of association, contiguity and similarity, are retained, and much use is made of them in explaining transference, trains of ideas, com. plexes, but the operation of association links appears to be completely controlled by instinctive and emotional dispositions. The machinery of association is the same as in the older doctrines, but the levers are operated by forces which lie quite outside the ken of association psychology.

Association figures also in the motor theory of consciousness, and here it would seem to be more after the old pattern. All association is between movement systems. Contiguity and similarity must be interpreted as contiguity and similarity between the systems of incipient and overt movements involved in the associated ideas.

We have said that Locke left his afterthought, his union of ideas by association, unreconciled with, or unrelated to, his account of knowing. Knowledge is the perception of the connexion of and agreement, or disagreement and repugnancy, of any of our ideas. In Book IV. he gives us a classification of the kinds of connexions and repugnancies we thus perceive: identity, relation, co-existence or necessary connexion, real existence. It would be out of place to go into the details of each class. What is at once apparent is that in all varieties of knowing the knower is perceiving some kind of relation between his ideas. They are synthesised or united in virtue of a perceived agreement or repugnancy.

If we turn to contemporary psychology, we may compare this doctrine with the principles of cogni tion laid down by Prof. Spearman. Prof. Spearman calls his qualitative principles of cognition 'noegenetic'. He claims that they and they alone are generative of new items in the field of cognition. Familiar as these principles may be, I will venture to quote the second and the third. The second is the principle of the eduction of relations : "The mentally presenting of any two or more characters (simple or complex) tends to evoke immediately a knowing of relation between them ". The third is the principle of the eduction of correlates: "The presenting of any character together with any relation tends to evoke immediately a knowing of the correlate character ". These two principles make the knowing of relations the basic fact of cognition. They are the key to intelligence.

Prof. Spearman would agree with Gestalt psychologists in stressing organisation. He differs from them by regarding organisation as dependent upon perceiving characters as related. All organisation or synthesis depends ultimately upon cognised relations. He thus denies sensory organisations as 
simple data. By his second principle he necessarily repudiates association in the Lockian sense. Although he keeps the names of the old laws of association, contiguity and similarity, he states explicitly that "quasi-mechanical reproductive adherence has its source in the noetic coherence". In principle, reproduction by association and the eduction of correlates are akin. The distinction is that in reproduction the relata have already been related in past experience, the organisation is old, whereas in eduction of correlates the educed correlate is new. It is this aspect of his third principle in creating new knowledge that Prof. Spearman wishes to stress, and it is just this stress that differentiates his principle from that of relative suggestion advocated by Thomas Brown in his "Philosophy of the Human Mind ", 1820. Whether such a distinction of 'old' ahd 'new' is one that can he drawn in any absolute sense is a question that need not be raised in this connexion.

Locke left us with unreconciled methods and principles, and in connecting these with differing schools in contemporary psychology, I may seem to be emphasising divergencies of doctrine. Indeed, I may seem to be giving support to the gibe that to-day there is no psychology, only a collection of psychologies. By many this is thought to be a sure sign of decadence. At first sight there is much in the present situation which may give rise to a sense of disappointment to those of us who belong to the older generation. The present century opened full of hope-psychology was emerging as a new science. It was being recognised as some- thing distinct both from philosophy and from physiology. It was rapidly developing a technique of its own. All was 'set fair' for the growth of the 'new' psychology. It is true there were schools in a very limited sense. There was Leipzig, Göttingen, Paris, Harvard, Cornell, etc., but the lines of cleavage represented, say, at the Paris Congress of 1900 , were but deep furrows in a common experimental field. To-day the schools appear to be separated by unbridged gulfs. Yet it is little more than fifty years since Wundt opened his laboratory in Leipzig, and fifty years is a brief interval in historical retrospect.

Is the present division of theory really a bad sign? Does it indicate the "petering out' of the spirit which animated the workers from 1879 to 1900 , or is it a sign of vigour? I believe there are good grounds for believing the latter alternative. Prof. Woodworth, in his book "Contemporary Schools of Psychology ", declares, " all the schools are emphasising something that demands emphasis and serve a useful function in the progress of psychology". The methods and principles which find a place in Locke's Essay may demand for their reconciliation, not resolution but increase of knowledge, to enable us to mark out their respective spheres.

If Prof. Woodworth is right, we need reject no 'psychology' as false, but rather consider how far its particular teaching serves to explain certain aspects of complex human phenomena. This thesis can be illustrated by applying it to the data of experiments on recall.

\section{Obituary}

Mr. E. EDSER

$\mathrm{M}$ ANY students of physics, as well as numerous friends in the world of applied science, will regret to learn that Mr. Edwin Edser died on Aug. 17, at sixty-six years of age, after a long period of acute suffering bravely borne. He was one of the most unassuming of men, yet everyone who knew him appreciated the breadth and depth of his knowledge of all branches of physics, and his clear understanding of fundamental principles used either in theory or in practice.

Mr. Edser was a student at the Royal. College of Science, South Kensington, and obtained his associateship in physics in 1892, being top of the list. After a year of research he was appointed demonstrator in physics at the College, under Sir Arthur Rücker, and in 1895 became lecturer in physics and head of the mathematical department of the South-Western Polytechnic, Chelsea. Later, he was lecturer in physics at Woolwich Polytechnic, and from 1903 until 1914 was head of the Department of Physics at Goldsmiths' College,University of London.

While at the Royal College of Science, Mr. Edser carried out some notable pieces of research and was associated with Sir Arthur Rücker in an im. portant paper on the objective reality of combination tones, read before the Physical Society in March 1895. The question of the objective exist- ence of summation tones as distinguished from supposed beat tones, which had previously been the subject of much controversy, was proved conclusively by the experiments and results described in this paper.

Mr. Edser was an ingenious experimenter, and so long ago as Aug. 17, 1893, he contributed an article to NATURE upon a simple arrangement of apparatus devised by him to illustrate Michelson's method of obtaining interference bands. The use of this apparatus in connexion with experiments on change of phase of light after reflection at a silver surface was described by him in an article in NatURE of Sept. 23, 1897. Mr. Edser was probably one of the earliest experimenters in Great Britain to make use of the principle of Michelson's interferometer, and he applied it to investigate the effect of movement in liquids upon the velocity of light. He also used the instrument in an investigation with Mr. S. G. Starling on the effect of the electric discharge upon the velocity of light. In a paper read before the Royal Society in 1898, Mr. Edser developed Maxwell's electromagnetic theory of light so as to include dispersion, metallic reflection, and allied phenomena.

In a letter to NATURE of May 2, 1912, concerning peculiar shadows cast by leaves during the partial solar eclipse of April 17, 1912, Mr. Edser made the

No. 3280 , VoL. 130] 